\title{
Impact of Emotional Exhaustions on Turnover Intentions: A Mediating Role of Organizational Commitment in Higher Education Institutes of Saudi Arabia
}

\author{
Nazar Omer Abdallah Ahmed ${ }^{1}$
}

\begin{abstract}
:
Environment, organizational culture, development/promotion policies, facilities, compensation and political issues are some of the causes of reduction in the organizational commitment and increase in the level of emotional exhaustion and development of turnover intention among faculty of universities. The occupational psychology of faculty is influenced by diverse elements and specifically, there are various factors that play crucial role in overall organizational commitment emotional exhaustion and turnover intention. The faculty plays a vital role in ensuring the students and society for the quality education. For this study, the faculty members of various departments of selected universities in Riaz, KSA were the target population. The population for this study comprised faculty members of higher education institutions employing approximately 100 or more than 100 faculty members. The results show that all the study variables are significantly related with each others. The mediation results show that organizational commitment partially mediate between the emotional exhaustion and turnover intentions among the faculty of higher education institutions in Saudi Arabia.
\end{abstract}

Key Words: Emotional Exhaustion, Organizational Commitment, Turnover Intentions, Mediation

\footnotetext{
${ }^{1}$ College of Science and Humanities Studies, Business Administration Department, Prince Sattam bin Abduaziz University, Kingdom of Saudi Arabia, nazaromer@gmail.com
} 


\section{Introduction}

Faculty retention is becoming an important issue for higher education institutions in KSA for various reasons. Ubiquitous presence of higher education institutions and particularly private institutes has provided the opportunities to faculty to switch over from institute to institute for better environment, facilities and compensation. The literature identifies the environment, organizational culture, development/promotion policies, facilities, compensation and political issues as some of the causes of reduction in the organizational commitment and increase in the level of emotional exhaustion and development of turnover intention among faculty of universities. The faculty has always been striving to get the required facilities and environment for improved performance. Universities are centers of career development either for teachers or students. The occupational psychology of faculty is influenced by diverse elements and specifically, there are various factors that play crucial role in overall organizational commitment emotional exhaustion and turnover intention.

The faculty plays a vital role in ensuring the students and society for the quality education. It is only possible when the faculty is vigorous with continuous dedication to an institution and students and completely absorbed in academic activities. Faculty not emotionally exhausted, does not develop cynical attitude and feel that they are contributing towards the progress of students and the institution. Further, the commitment of faculty is integral to institutions. They may develop affection towards the university, feel that leaving the institution would be costly and believe that the problems of institutions are their own. The issue then is whether universities provide an encouraging environment to the faculty so that they may improve commitment, reduce the level of emotionally exhaustion and intention to leave job.

The focus of current research study is to comprehend the relationship among commitment, emotional exhaustion and turnover intention and to understand the mediating role of organizational commitment between work outcomes e.g. emotional exhaustion and turnover intentions. The study will also comprehend the relationship of various dimensions of organizational commitment with emotional exhaustion and turnover intentions

\section{Literature Review}

\section{Emotional Exhaustion}

The depletion of employee's emotional and mental stress that affects the psychological involvement in organization considered as emotional exhaustion. Maslach and Jackson (1981) defined emotional exhaustion in a sense that "workers feel they are no longer able to give themselves at a psychological level". The employee feel tired, fatigued and their emotional energies are exhausted, persistence of such feelings becomes chronic and long lasting, the workers are considered as 
emotionally exhausted. "The emotionally exhaustion normally experienced in human services organizations" (Maslach, 1981, 1986). The organizational objectives badly suffer setbacks due to emotional exhaustion because employee does not take expected interest and it becomes ever worse when the feelings become chronic. Demerouti et al. (2005) applied Oldenburg Burnout Inventory to appraise and determine dimensions of burnout and concluded that prolong mental wear and tear as the exhaustion not the emotional exhaustion, even though the constructs are very similar. A whole issue of research journal work and Stress in 2005 exclusively focused on this dimension of burnout. A large number of scholars in the issue of journal agreed, "Emotional exhaustion is the integral dimension of burnout" (Halbesleben et al., 2004). Kristensen et al. (2005) commented in the favor of emotional exhaustion as one factor construct of burnout. Demerouti (2004) applied Copenhagen Burnout Inventory and used only one dimension, emotional exhaustion to assess the level of burnout among employees. Besides Demerouti (2004), Bakker et al. (2005) also adopted one-dimensional approach and used only the items of emotional exhaustion from Maslach Burnout Inventory to evaluate level of burnout.

\section{Organizational Commitment}

Organizational commitment is the psychological attachment of an employee with the organization. It is the consequence of continuous affection of employee with the organization. Moreover, "Organizational commitment is the relative strength of an employe's identification with and involvement in a particular organization" (Mowday et al., 1982). Further, elucidating the organizational commitment in academic organizations, "commitment is a binding force for on's loyalty, identification, and involvement with an educational institution" (Ciriello, 1987). "Organizational commitment is viewed as an important variable in facilitating the understanding of an employee's attitudes and behavior in the workplace" (Hui and Lee, 2000).

The organizational commitment has been the focus of attention of the researchers on occupational psychology. Allen and Meyers (1990) have described "Organizational commitment has been defined in a wide variety of opinions yet no consensus on defining organizational commitment has been reached over the past years". Furthermore, "the concept has also attracted considerable attention in the field of organizational behavior" (Mathieu and Zajac, 1990) and most importantly, "the research on organizational behavior has various important work-related attitudes such as job satisfaction and turnover as well as non-work behavior such as organizational citizenship behavior" (Allen and Meyer, 1996, Randall, Fedor and Longenecker,1990, Roodt, 2004a).

Therefore, earlier studies have defined the concept commitment as a "unidimensional construct based on employees' emotional attachment to the organization (attitudinal perspective)" (Mowday et al., 1979, Porter, Steers, Mowday and Boulian, 1974). While other defines it in relation to "costs associated with 
leaving the organization (behavioral perspective)" (Meyer and Parfyonova, 2010).

\section{Turnover Intention}

Turnover intention among the employees is one of the variables of this study. Turnover intention is an important predicament for the organizations because sometimes it produces very costly results. "When turnover went down organizational performance increased (Halbrook, Meder, Stuchlik and Thorpe 1991). This leads to a reduction in costs associated with retraining and hiring.

A study by Boxall et al. (2003) conducted in New Zealand on turnover concluded that inspiration or stimulus of turnover intention is multidimensional no single factor contribute to the employees approach towards turnover. Most significant factors, such as, "age, tenure, overall satisfaction, job content, intention to remain on the job, and commitment were all negatively related to turnover (i.e. the higher the variable, the lower the turnover)" (Mobley et al, 1982).

However, Griffeth et al. (2000) have explored that reduction in job satisfaction; organizational commitment and comparison of alternatives are some of the organizational factor that creates turnover intention among employees.

\section{Emotional Exhaustion and Turnover Intention}

There are several undesirable effects that result from the occurrence of emotional exhaustion and encompass direct effects such as poor job performance (Davidson, Timo, Ying Wang, 2010). Studies have shown emotional exhaustion to be significantly correlated with several work-related outcomes including voluntary turnover among employees (Maslach \& Jackson, 1986; Wright \& Cropanzano, 1998), job performance (Cropanzano et al., 2003) and turnover intentions (Yavas et al., 2008; Karatepe and Uludag, 2007).

\section{Study Model}

A considerable number of works in the human resources literature have identified organizational commitment as the most important antecedent of turnover intention (Porter et al., 1974; Ohana and Meyer, 2010). "Organizational commitment, turnover intention could influence human resource policies and practices" (Rayton, 2006; Armutlulu and Noyan, 2011). Various researchers examined the relationship between organizational commitment and turnover intention and found that a negative relationship exists between these two constructs (Kim and Brymer, 2011).

The concept of emotional exhaustion has been associated with different work outcomes e.g. job withdrawal, absenteeism, low commitment and intention to leave (Leiter and Maslach 2009). Whereas, in the employees, who stay with the organization the high level of emotional exhaustion leads to reduced effectiveness 
and low productivity. Simultaneously, high level of commitment leads to low turnover intention. Although the relationship of organization commitment, and emotional exhaustion and turnover intention is established in the literature separately but a few studies of such kind have been carried out, that delineates the mediation of organization commitment between emotional exhaustion and turnover intention of faculty of universities. Study model suggest that organization commitment play mediating role between emotional exhaustion and turnover intentions among the faculty of universities.

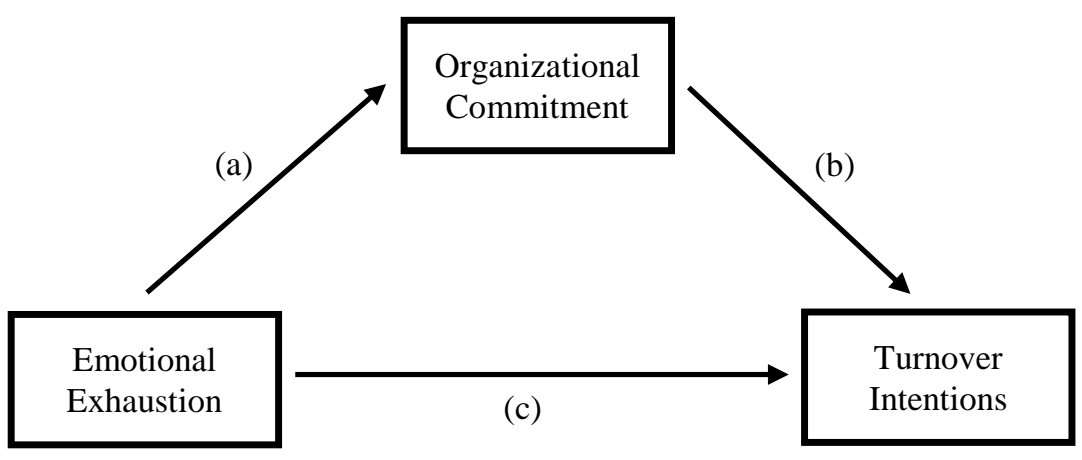

\section{Hypotheses}

H1: Organizational commitment negatively and significantly predicts turnover intention among the faculty of universities.

H2: Emotional exhaustion positively predicts turnover intention among the faculty of universities.

H3: Emotional exhaustion negatively and significantly predicts organizational commitment among faculty of universities.

H4: Organizational Commitment mediates the relationship between Emotional Exhaustion, and Turnover Intention of faculty of universities.

\section{Methodology}

A cross sectional survey method was carried out for the data collection for this study. The faculty members of various departments of selected universities in Riaz were the target population. The population for this study comprised faculty members of higher education institutions employing approximately 100 or more than 100 faculty members. A convenient sampling technique was applied for the sample selection from the universities in Saudi Arabia. The convenient sampling method has been frequently used in occupational psychology studies. Brand (2012) used it in a study in South Africa, Bakker (2005); Demerouti (2010) and Pedro (2012) used 
convenient sampling in different studies on occupational psychology.

\section{Instruments}

The emotional exhaustion is measured through MBI-GS (Maslach and Leiter 1997). It includes five items Emotional exhaustion (the feeling of being emotionally depleted and feeling stress during work). Emotional exhaustion is measured with five items $(\alpha=$.93) "I feel emotionally drained from my work". The respondents were asked to indicate the extent to which they agreed with each statement using a five-point rating scale $(1=$ Never, $5=$ Everyday $)$. Organizational commitment dimensions were measured using six items from Meyer and Allen se (1990) commitment scale, two items of affective commitment $(\alpha=.91)$, two items from continuous commitment $(\alpha=.92)$ and two items of normative commitment $(\alpha=.90)$ were included in the questionnaire. The responses would be recorded on five point Likert scale from (1) Strongly Agree to (5) Strongly Disagree. Turnover intention among the faculty would be measured by three items from Nissly et al. (2005) fouritem scale of intention to leave. The items include, "In the next few months I intend to leave this organization" ( $\alpha=.90)$ "In the next few years I intend to leave this organization" ( $\alpha=.91)$ and "I occasionally think about leaving this organization" $(\alpha$ =.92). These items were rated on a five-point Likert scale ranging from (1 "strongly Disagree" to 5"strongly Agree").

\section{Results}

Table 1. Correlation

\begin{tabular}{ccccccc} 
VariablesM & & EE & AC & CC & NC & TI \\
\hline Ex & 1.8 & 1.0 & $.47^{* *}$ & $-.46^{* *}$ & $-.52^{* *}$ & $.60^{* *}$ \\
AC & 4.0 & & 1.0 & $.87^{* *}$ & $.83^{* *}$ & $-.68^{* *}$ \\
CC & 4.0 & & & 1.0 & $.86^{* *}$ & $-.73^{* *}$ \\
NC & 4.0 & & & & 1.0 & $-.77^{* *}$ \\
TI & 1.9 & & & & & 1.0
\end{tabular}

**. Correlation is significant at the 0.01 level (2-tailed).

The dimensions of organizational commitment were negatively and significantly correlated with emotional exhaustion. The effective commitment is negatively and significantly related with emotional exhaustion at $(\mathrm{r}=-.47, \mathrm{p}<.01)$. The continuous 
commitment was negatively and significantly related with emotional exhaustion at $(\mathrm{r}=-.46, \mathrm{p}<.01)$. Normative commitment was negatively and significantly related with emotional exhaustion at $(\mathrm{r}=-.52, \mathrm{p}<.01)$.Emotional exhaustion at $(\mathrm{r}=.60, \mathrm{p}<$ $.01)$ is positively and significantly related with turnover intension. The turnover intention was also significantly and negatively related with dimension of commitment, affective commitment at $(r=-.68, p<.01)$ continuous commitment at $(\mathrm{r}=-73, \mathrm{p}<.01)$ at normative commitment at $(\mathrm{r}=-.77, \mathrm{p}<.01)$.

Table 2. Correlation among Study Variable

\begin{tabular}{l}
\multicolumn{1}{c}{$\begin{array}{c}\text { Variables } \\
\text { Exhaustion }\end{array}$} \\
$\begin{array}{l}\text { Emotional } \\
\text { Exhaustion }\end{array}$
\end{tabular}




\section{Dependent variable: Organizational Commitment}

It was hypothesized that there is negative relationship between emotional exhaustion and organizational commitment among faculty of universities. The $\mathrm{R}^{2}=.47$ results show that burnout account for $47 \%$ negative and significant variation in the organizational commitment level. Emotional exhaustion $(\beta=-.60, p<.05)$ shows negative and significant relations with organizational commitment.

\section{Emotional Exhaustion and Turnover Intention}

The study investigated the role of emotional exhaustion in predicting the turnover intention among the faculty of universities. Emotional exhaustion was regressed on the turnover intension to find out the positive and significant relationship of emotional exhaustion in creating turnover intentions among the respondents. The result of the analysis is discussed below:

Table 4. Adjusted R

\begin{tabular}{lllclc}
\hline Variable & $\mathrm{R}$ & $\mathrm{R}^{2}$ & $\begin{array}{c}\text { Adjusted } \\
\mathrm{R}^{2}\end{array}$ & $\beta$ & $\mathrm{Sig}$ \\
\hline $\begin{array}{l}\text { Emotional } \\
\text { Exhaustion }\end{array}$ & .71 & .51 & .50 & & \\
& & & & .70 & .000
\end{tabular}

The $\mathrm{R}=.71$ shows that there is high level of correlation between emotional exhaustion and turnover intention. The $\mathrm{R}^{2}=.51$ shows that emotional exhaustion contribute for $51 \%$ variation in the level of turnover intention. The $(\beta=.70, p<.01)$ show that emotional exhaustion account for $70 \%$ positive and significant variation in the turnover intentions.

\section{Mediation Analysis}

The mediation models explain the system by which the independent variable (Emotional Exhaustion) exercises their influence on the dependent variable (turnover intention) and this influence is mediated by the construct organizational commitment. It has been hypothesized that increases in the level of emotional exhaustion among faculty of universities lead to develop turnover intentions among them. The mediation variables organizational commitment serves to clarify the nature of relationship between emotional exhaustion and turnover intentions of faculty.

The procedure for testing for mediation, as described by Barron and Kenny (1986) is applied for testing the mediation on the proposed variables. Testing for mediation involves establishing four conditions: 
There is positive and significant relationship of emotional exhaustion with turnover intention (Path c).

There is significant negative relationship between emotional exhaustion and organizational commitment (Path a).

The relationship of organizational commitment with turnover intention is significantly negative (Path b).

Controlling the effect of MV on DV, the effect of IV and DV is no longer significant.

These conditions are tested by performing three separate regression analyses.

Table 5. Analysis One (Path c)



\section{Dependent Variable: Turnover Intention}

The regression analysis shows that $\left(\mathrm{R}^{2}=.50\right) 50 \%$ variation in the turnover intentions of the faculty members of universities is the result of level emotional exhaustion among them. There $(\beta=.32, \mathrm{p}<.01)$ explain that emotional exhaustion contribute significant and positive impact on turnover intention of the faculty. The first condition regarding the (path c) suggested by of the Barron and Kenny (1986) has been met.

Table 6. Analysis One (Path a)

\begin{tabular}{|c|c|c|c|c|c|}
\hline Variable & $\mathrm{R}$ & $\mathrm{R}^{2}$ & $\begin{array}{c}\text { Adjusted } \\
\mathrm{R}^{2}\end{array}$ & $\beta$ & Sig \\
\hline \multirow[b]{2}{*}{ Emotional Exhaustion } & .68 & .47 & .46 & & \\
\hline & & & & -.60 & .011 \\
\hline
\end{tabular}

\section{Dependent Variable: Organizational Commitment}


Table 7. Analysis (Path b)

\begin{tabular}{lccccc}
\hline Variable & $\mathrm{R}$ & $\mathrm{R}^{2}$ & $\begin{array}{c}\text { Adjusted } \\
\mathrm{R}^{2}\end{array}$ & $\beta$ & $\mathrm{Sig}$ \\
\hline & .77 & .59 & .59 & & \\
Organizational Commitment & & & & -.77 & .000 \\
\hline
\end{tabular}

The regression results show that $47 \%$ variation is predicted by emotional exhaustion in the organizational commitment of faculty members of universities. The $(\beta=-.60$, $\mathrm{p}<.01$ ) shows that emotional exhaustion explains $60 \%$ significant negative variation in the organizational commitment. The results of analysis show that the first mediation condition suggested by Barron and Kenny (1986) has been fulfilled.

\section{Dependent Variable: Turnover Intention}

The regression coefficients at step two show that organizational commitment is significantly (and negatively) related to turnover intentions, thus meeting the third condition for mediation (path b). $(\beta=-.77, p<.01)$ explains that there is strong relationship between organizational commitment and turnover intentions. Organizational commitment predicts $77 \%$ variation in the level of organizational commitment.

Table 8. Mediation Analysis

\begin{tabular}{lccccc}
\hline Variable & $\mathrm{R}$ & $\mathrm{R}^{2}$ & $\begin{array}{c}\text { Adjusted } \\
\mathrm{R}^{2}\end{array}$ & $\beta$ & $\mathrm{Sig}$ \\
\hline Model I & .70 & .50 & .49 & .32 & .000 \\
$\begin{array}{l}\text { Emotional Exhaustion } \\
\text { Model II }\end{array}$ & .81 & .66 & .66 & & \\
& & & & .25 & .000 \\
$\begin{array}{l}\text { Emotional Exhaustion } \\
\text { Organizational Commitment }\end{array}$ & & & & -.56 & .000 \\
\hline
\end{tabular}

\section{Dependent Variable: Turnover Intentions}

Model I shows $(\beta=.32, \mathrm{p}<.01)$ for emotional exhaustion describe that $32 \%$ change in the organizational commitment is due to emotional exhaustion. Model II, due to inclusion of mediating variable, organizational commitment the impact of emotional exhaustion reduced to $(\beta=-.25, p<.01) 25 \%$. The beta for controlled regulation (path c), which was significant in the first analysis is still significant when controlling for the effects of the organizational commitment. Thus the final condition for demonstrating mediation has not been completely fulfilled. So it can be concluded 
that organizational commitment does not completely but partially mediate between emotional exhaustion and turnover intentions of universities. The above result explains that increase in the level emotional exhaustion among the faculty members of universities may lead to turnover intentions but these intentions may partially be influenced by their level commitment towards the institution. The mediation result shows that organizational commitment partially mediated between emotional exhaustion and turnover intentions among the faculty so the hypothesis of the study is partially supported.

\section{Discussion and Conclusion}

This study is carried out with a vision to comprehend the level of emotional exhaustion and its relationship with work outcomes such as organizational commitment and turnover intention among the faculty of universities. Further, the study has also evaluated the mediation effects of organizational commitment between emotional exhaustion and turnover intention among faculty universities. The study proposed that the emotional exhaustion has negative relationship with organizational commitment and positive relationship with turnover intentions. Emotional exhaustion $(\beta=-.11, \mathrm{p}<.01)$ explain negative influence on the commitment level of the respondents.

Regarding emotional exhaustion, results of this study are in line with Mathieu and Zajac, (1990); Antosnovsky, (1979). Emotional exhaustion $(\beta=.30, p<.01)$ is positively and significantly predicting turnover intention among the university faculty. The same results are reported by Leiter and Maslach (2009); De Croon et al (2004); Lee and Ashforth, (1996); Söderfeldt et al. (1995) in different studies on the relationship between emotional exhaustion and turnover intention.

Furthermore, the study also concluded that the relationship between organizational commitment and turnover intentions among the faculty are significantly negative. The result is in consistent with study of Vandenberghe and Tremblay (2008). The results of the study supported majority of the hypotheses and some interesting and unique results are exhibited.

Brewer and McMahan (2004) concluded in study that faculty of universities show low levels of emotional exhaustion, the current study support these findings. So the management of the universities should create clear and consistent communication with faculty, improve organizational culture to improve engagement and commitment.

Provide rewards and benefits to faculty who show signs of engagement and commitment, consistently listening to the needs and demands of the faculty and telling the faculty about their significance to the organizational goals in particular and university in general. 


\section{References}

Allen, N. J. \& Meyer, J. P. (1990). The measurement and antecedents of affective, continuance and normative commitment to the organization. Journal of Occupational Psychology, Vol. 63: 1-18.

Allen, N. J. \& Meyer, J. P. (1996). Affective, continuance and normative commitment to the organization: An examination of construct validity. Journal of Vocational Behavior, Vol. 49: 252-276.

Antonovsky, A. (1979). Health, stress and coping. San Francisco: Jossey- Bass.

Armutlulu, I. H.; and Noyan, F. (2011), "A multilevel of organizational commitment", Procedia - Social and Behavioral Sciences, Vol.30, pp.2139-2143.

Bakker, A.B., Le Blanc, P.M., and Schaufeli, W.B. (2005). Burnout contagion among nurses who work at intensive care units. Journal of Advanced Nursing, 51, 276-287. Behavioral Sciences , 25, 131-132.

Brand-Labuschagne, K. Mostert, S. Rothmann \& J.C. Rothmann (2012) Burnout and work engagement of South African blue-collar workers: The development of a new scale. Southern African Business Review Vol (16) Number, pages 58-93.

Baron ,R. \& Kenny, D (1986). The Moderator-Mediator Variable Distinction in Social Psychological Research: Conceptual, Strategic, and Statistical Considerations. Journal of Personality and Social Psychology 51, 1173-1182.

Brewer, E.W. \& Shapard, L. (2004). Employee burnout: A meta-analysis of the relationship between age or years of experience. Human Resource Development Review, 3(2), 102 123.

Halbesleben, J.R.B. and Buckley, M.R. (2004) Burnout in organizational life. Journal of Management, Vol. 30, pp. 859-79.

Ciriello, M. J. (1987) Teachers in catholic schools: A study of commitment (Doctoral dissertation, The Catholic University of America, 1987). Dissertation Abstracts International, 48, 522.

De Croon, E.M., Sluiter, J.K., Blonk, R.W. B., Broersen, J.P.J., \& Frings-Dresen, M.H.W. (2004). Stressful work, psychological job strain, and turnover: A two-year prospective cohort study of truck driver. Journal of Applied Psychology, 89(3), 442-454.

Demerouti, E., Bakker, A.B. and Bulters, A.J. (2004), "The loss spiral of work pressure, work-home interference and exhaustion: reciprocal relations in a three-wave study", Journal of Vocational Behavior, Vol. 64, pp. 131-49.

Demerouti, E., Bakker, A.B., Nachreiner, F. and Schaufeli, W.B. (2001a), "The job demands-resources model of burnout", Journal of Applied Psychology, Vol. 86, pp. 499-512.

Demerouti, E., Bakker, A.B., Nachreiner, F. and Schaufeli, W.B. (2000), "A model of burnout and life satisfaction among nurses", Journal of Advanced Nursing, Vol. 32, pp. 454-64.

Demerouti, E., Bakker, A.B., De Jonge, J., Janssen, P.P.M. and Schaufeli, W.B. (2001b), "Burnout and engagement at work as a function of demands and control", Scandinavian Journal of Work, Environment and Health, Vol. 27, pp. 279-86.

Demerouti, E., Bakker, A. B., de Jonge, J., Janssen, P. P. M., and Schaufeli, W. B. (2010).Burnout and engagement as a function of demands and control. Scandinavian Journal of Work Environmental Health, 27, 279-286.

Griffeth R. W., Hom P. W. \& Gaertner S. (2000), „A Meta-analysis of antecedents and correlates of employee turnover: Update, moderator tests, and research Implications for the next millennium "e, Journal of Management. vol. 26(3), pp.463-488. 
Hui, C., and Lee, C. (2000). Moderating effects of organizational-based self-esteem on Inventory: A critical review and re-conceptualization. Journal of Applied Psychology. Investigating the English translation of the Oldenburg Burnout Inventory. Work and Stress, 19, $208-220$.

Ketchand, A.A.; Strawser, J.R(1998). The existence of multiple measures of organizational commitment and experience related differences in a public accounting setting. Behavioral Research in Accounting 110, 109-137.

Kim, S.W. and Mueller, C.W., 2011. Occupational and organizational commitment in different occupational contexts: the case of South Korea. Work and occupations, 38 (1), 3-36.

Kim, T., Park, S., and Chang, K., 2011. Antecedents of organizational citizenship behaviors among part-time employees of service organizations in Korea. Asia Pacific business review, 17 (1), 85-101.

Lee R. T., and Ashforth, B. E. (1996). A meta-analytic examination of the correlates of the three dimensions of job burnout. Journal of Applied Psychology, 8, 123-133.

Leiter. M,Maslach. C. (2009).Nursing Turnover: Mediating Role of Burnout. Journal of Nursing. Vol: 17. Pp 331-339.

Maslach, C., and Jackson, S. E. (1981a).The Maslach Burnout Inventory. Palo Alto, CA: Consulting Psychologists Press.

Maslach, C., and Jackson, S. E. (1981b).The measurement of experienced burnout. Journal of Occupational Behavior, 2, 99-113.

Maslach, C., Jackson, S. E., andLeiter, M. P. (1997). Maslach Burnout Inventory ( ${ }^{\text {rd }}$ ed.). In C. P. Zalaquettand R. J. Wood (Eds.), Evaluating stress: A book of resources. Lanham, MD: Scarecrow Press.

Maslach, C., and Leiter, M. P. (1997).The truth about burnout: How organizations cause personal stress and what to do about it. San Francisco, CA: Jossey-Bass.

Mathieu, J. E., \& Zajac, D. M. (1990). A review and meta-analysis of the antecedents, correlates and consequences of organizational commitment. Psychological Bulletin, 108, 171-194.

Mor Barak, M.E., Nissly, J.A., \& Levin, A. (2001). Antecedents to retention and turnover among child welfare, social work, and other human service employees: What can we learn from past research? A review and meta-analysis. Social Service Review, 75(4), $625-662$.

Mowday, R. T., Porter, L. W., and Steers, R. M. (1982). Employee organization linkages: The psychology of commitment, absenteeism, and turnover. New York: Academic Press.

Mowday, R. T., Porter, L. W., and Steers, R. M. (1979).The measurement of organizational commitment. Journal of Vocational Behavior, 14, 224-247.

Meyer, J.P. \& Allen, N.J. (1997). Commitment in the workplace: Theory, Research, and Application (Advanced Topics in Organizational Behavior). Thousand Oaks: Sage Publications, Inc.

Mobley, W.H. (1982). Some Unanswered Questions in Turnover with Withdrawn Research. The Academy of Management Review, 7/1: 111-116.

Nissly, J.A., Mor Barak, M.E., \& Levin, A. (2005). Stress, social support, and workerse intentions to leave their jobs in public child welfare. Administration in Social Work, 29(1), 79-100.

Ohana, M.; and Meyer, M. (2010), "Should I stay or should I go now? Investigating the intention to quit of the permanent staff in social enterprises", European Management Journal, No 28, pp. 441-454. 
Pedro Torrente, Marisa Salanova, Susana Llorens, Wilmar B. Schaufeli (2012) Teams make it work: How team work engagement mediates between social resources and performance in teams Psicothema. Vol. 24, No1, pp. 106-112.

Porter, L. W., Steers, R. M., Mowday, R. T., and Boulian, P. V. (1974). Organizational commitment, job satisfaction, and turnover among psychiatric technicians. Journal of Applied Psychology, 59, 603-609.

Randall, D. (1990). The consequences of organizational commitment: Methodological investigation. Journal of Organizational Behavior, 11, 361-378.

Roodt, G. (2004a). Concept redundancy and contamination in employee commitment research: Current problems and future directions. South African Journal of Industrial Psychology, 30(1), 82-90.

Rayton, B.A., (2006), "Examining the interconnection of job satisfaction and organizational commitment: an application of the bivariate probit model", International Journal of Human Resource Management, Vol. 17, No.1, pp.139-154.

Söderfeldt, M., Söderfeldt, B., \& Warg, L.E. (1995). Burnout in social work. Social Work, 40, 638-646.

Um, M.Y. \& Harrison, D.F. (1998). Role stressors, burnout, mediators, and job satisfaction: A stress-strain-outcome model and an empirical test. Social Work Research,22(2), $100-116$.

Vandenberghe, C. and Tremblay, M. (2008) "The role of pay satisfaction and organizational commitment in turnover intentions: A two-sample study", Journal of Business and Psychology, vol. 22, no. 3, pp. 275-286. 